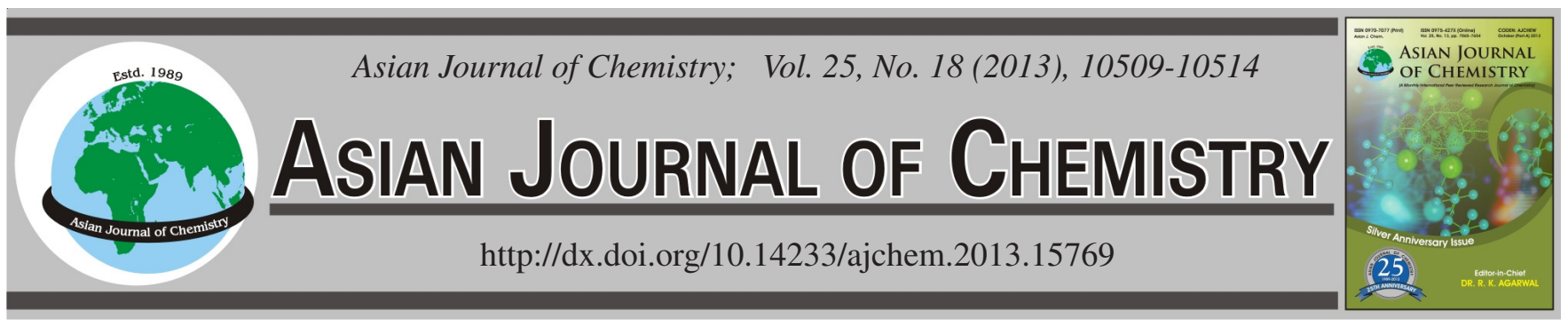

\title{
Adsorption Mechanism of Activated Carbon Fibre/Carbon Nanotube Composites for Rhodamine B from Aqueous Solution
}

\author{
Liping Wang ${ }^{1, *}$, Mingyu Zhang ${ }^{2, *}, Z_{\text {Hucheng Huang }}^{3}$, ChenXi ZhaO ${ }^{1}$ and XiJun Pei ${ }^{1}$
}

${ }^{1}$ Department of Biological Engineering and Environmental Science, Changsha University, Changsha 410003, Hunan Province, P.R. China ${ }^{2}$ State Key Laboratory for Powder Metallurgy, Central South University, Changsha 410083, Hunan Province, P.R. China

${ }^{3}$ School of Minerals Processing and Bioengineering, Central South University, Changsha 410083, Hunan Province, P.R. China

*Corresponding authors: Fax: +86 731 84261551; Tel: +86 731 84261424; E-mail: misswlp@163.com, mingyu@mail.csu.edu.cn

\begin{abstract}
Activated carbon fiber (ACF)/carbon nanotube (CNT) composites were fabricated by chemical vapor deposition and characterized with field emission scanning electron microscope, Fourier transformation infrared spectroscopy, pore size distribution and high resolution transmission electron microscopy. The SEM results showed high density carbon nanotubes were well-distributed on the surface of activated carbon fibers. The total volume, BJH mesopore volume and average pore diameter of ACF/CNT composites were $0.5832 \mathrm{~cm}^{3} / \mathrm{g}, 0.095$ $\mathrm{cm}^{3} / \mathrm{g}$ and $2.0140 \mathrm{~nm}$, respectively, which were greater than those of activated carbon fibers. The adsorption data for rhodamine B were well fitted with Langmuir adsorption isotherm and pseudo-second order kinetics equation. The adsorption rate was controlled by interparticle diffusion and film diffusion. Because the values of $\Delta \mathrm{G}$ were positive and the values of $\Delta \mathrm{H}$ and $\mathrm{E}_{\mathrm{a}}$ were $15.7 \mathrm{~kJ} / \mathrm{mol}$ and $0.113 \mathrm{~kJ} /$ mol, respectively, the adsorption was suggested non-spontaneous and endothermic physisorption. Hydrogen bond was main adsorption mechanism of ACF/CNT composites for rhodamine B from aqueous solution.
\end{abstract}

Key Words: Activated carbon fiber/carbon nanotube composites, Rhodamine B, Adsorption isotherms.

\section{INTRODUCTION}

At present, dyes have been extensively used in the textile, leather, paper, plastic and other industries. A lot of industrial wastewater containing dyes has been discharged to water every year $^{1,2}$. Most of the dyes were organics with bio-toxicity and not readily biodegradable due to strong inoxidizability, which give rise to the ravage of the water ecosystem because the discharge of low concentration dye wastewater could greatly reduce the light transmittance of water and affect microorganic growth $^{2,3}$. Therefore, the removal of dyes from wastewater has become an important environmental issue. Now, main treatment technologies include chemical coagulation ${ }^{4-6}$, biological treatment $^{7,8}$, membrane separation ${ }^{9-11}$, electrochemistry ${ }^{12-15}$, chemical oxidation $^{16-18}$, photocatalytic degradation ${ }^{19-22}$ and adsorption ${ }^{23-26}$. Through comparative analysis of the previous treatment methods, adsorption has been found to be superior to other techniques for treating dye wastewater because it was lowcost, highly efficient, simple, easy to perform and insensitive to toxic substances.

Rhodamine B is a typical cation dye and widely used. Mineral materials ${ }^{27}$, activated carbon ${ }^{28}$, resin $^{29}$ and nanomaterials ${ }^{30}$ have been common adsorbents for rhodamine B. Among these adsorbents, CNTs had advantageous of large specific surface area and adsorption capacity and $\pi-\pi$ bond was easily formed by the interactions of big $\pi$ bond of CNTs and conjugated $\pi$ bond of rhodamine B molecules ${ }^{31}$. Recently, there has been much research on the adsorption of CNTs for dyes from aqueous solution ${ }^{24,32-34}$ and these results showed the adsorption properties of CNTs for dyes were excellent. However, CNTs have the disadvantages of light weight, small volume and difficult separation from solution. Consequently, activated carbon fiber (ACF)/carbon nanotube (CNT) composites were prepared and their adsorption mechanism for rhodamine B from aqueous solution was investigated in the paper.

\section{EXPERIMENTAL}

Viscose activated carbon fibers produced by Jiangsu sutong carbon fiber limited company were used and the purity of $\mathrm{H}_{2}, \mathrm{~N}_{2}$ and $\mathrm{C}_{2} \mathrm{H}_{2}$ was $99.99,99.99$ and $99.9 \%$, respectively. The concentration of $\mathrm{HNO}_{3}$ was 65-69\% and the other chemicals were of analytical grade. The molecular structure of rhodamine B was shown in Fig. 1. The molecular size of rhodamine B was $1.50 \mathrm{~nm} \times 1.31 \mathrm{~nm} \times 0.51 \mathrm{~nm}$.

Preparation of ACF/CNT composites: ACF/CNT composites were prepared in the quartz tube reactor which was 
<smiles>CCN(CC)c1ccc2c(-c3ccccc3C(=O)O)c3ccc(=[N+](CC)CC)cc-3oc2c1</smiles>

Fig. 1. Molecular structure of rhodamine B

placed in the vertical tube furnace. Firstly, ACFs were impregnated in $\mathrm{HNO}_{3}$ and $0.05 \mathrm{~mol} / \mathrm{L}$ nickel nitrate solution in sequence. Secondly, dried ACFs were put at the constant temperature region of the quartz tube reactor and their temperature increase to $450{ }^{\circ} \mathrm{C}$ in the $\mathrm{N}_{2}$ atmosphere, then nickel nitrate decomposed into nickel oxide. After that, nickel oxide was reduced to nanocrystalline $\mathrm{Ni}$ under $\mathrm{H}_{2}$ atmosphere and the temperature reached $650{ }^{\circ} \mathrm{C}$ in the $\mathrm{N}_{2}$ atmosphere. The catalytic pyrolysis reaction of $\mathrm{C}_{2} \mathrm{H}_{2}$ began to carry out in both $0.3 \mathrm{~L} / \mathrm{min} \mathrm{H}_{2}$ and $40 \mathrm{~mL} / \mathrm{min} \mathrm{C}_{2} \mathrm{H}_{2}$. Finally, the reactor was cooled to room temperature in the $\mathrm{N}_{2}$ atmosphere after $20 \mathrm{~min}$ reaction.

Characterization: The surface morphology was observed with FEI Nova Nano SEM230. NEXUS670 Fourier transform infrared spectrometer was used to determined the surface groups of samples. The pore size distribution was ascertained by Quantachrome SI pore size distribution tester. The internal structure was detected by JEM-3010 HRTEM. The concentration of rhodamine B in aqueous solution was tested by UV759 ultraviolet and visible spectrophotometer.

Adsorption studies: A certain amount of adsorbent and $100 \mathrm{~mL}$ rhodamine $\mathrm{B}$ solution in a certain concentration were put into $250 \mathrm{~mL}$ conical flasks and the $\mathrm{pH}$ of solution was adjusted with $\mathrm{HCl}$ and $\mathrm{NaOH}$ solutions. Then, conical flasks were covered and placed in constant temperature shaker, then shaken for a time at $120 \mathrm{r} / \mathrm{min}$. The concentration of solution after adsorption was measured at the wavelength of maximum absorbance of $554 \mathrm{~nm}$. The adsorption capacity could be calculated according to the following formula.

$$
\mathrm{q}_{\mathrm{e}}=\left(\mathrm{c}_{0}-\mathrm{c}_{\mathrm{e}}\right) \mathrm{V} / \mathrm{m}
$$

where, $\mathrm{q}_{\mathrm{e}}$ is adsorption capacity at equilibrium $(\mathrm{mg} / \mathrm{g}), \mathrm{c}_{0}$ is the initial concentration of solution $(\mathrm{mg} / \mathrm{L}), c_{\mathrm{e}}$ is the equilibrium concentration of solution $(\mathrm{mg} / \mathrm{L}), \mathrm{V}$ is solution volume $(\mathrm{L})$ and $\mathrm{m}$ is adsorbent dose $(\mathrm{g})$.

\section{RESULTS AND DISCUSSION}

Characterization of adsorbents: Fig. 2 shows the characterization graphs of the adsorbents. SEM of ACF/CNT composites are presented in Fig. 2a and it is seen that dense CNTs were well-distributed on the surface of ACFs. Fig. $2 b$ expresses that DFT pore size distribution curve. It is thus clear that the pore size distribution of ACF/CNT composites shifted to higher pore size comparing with that of ACFs. Calculations suggested the total volume, BJH mesopore volume and average pore diameter of ACF/CNT composites were $0.5832 \mathrm{~cm}^{3} / \mathrm{g}, 0.095$ $\mathrm{cm}^{3} / \mathrm{g}$ and $2.0140 \mathrm{~nm}$, respectively. However, the total volume, BJH mesopore volume and average pore diameter of
ACFs were $0.5288 \mathrm{~cm}^{3} / \mathrm{g}, 0.031 \mathrm{~cm}^{3} / \mathrm{g}$ and $1.6788 \mathrm{~nm}$, respectively. FTIR (Fig. 2c) showed that the intense absorption peaks at $3418 \mathrm{~cm}^{-1}$ and $3469 \mathrm{~cm}^{-1}$ attributed to the stretching vibration of associated $-\mathrm{OH}$ and these peaks of $\mathrm{ACF} / \mathrm{CNT}$ composites after adsorption greatly enhanced, indicating $-\mathrm{OH}$ participated in adsorption process and hydrogen bond was the most important adsorption mechanism of ACF/CNT composites
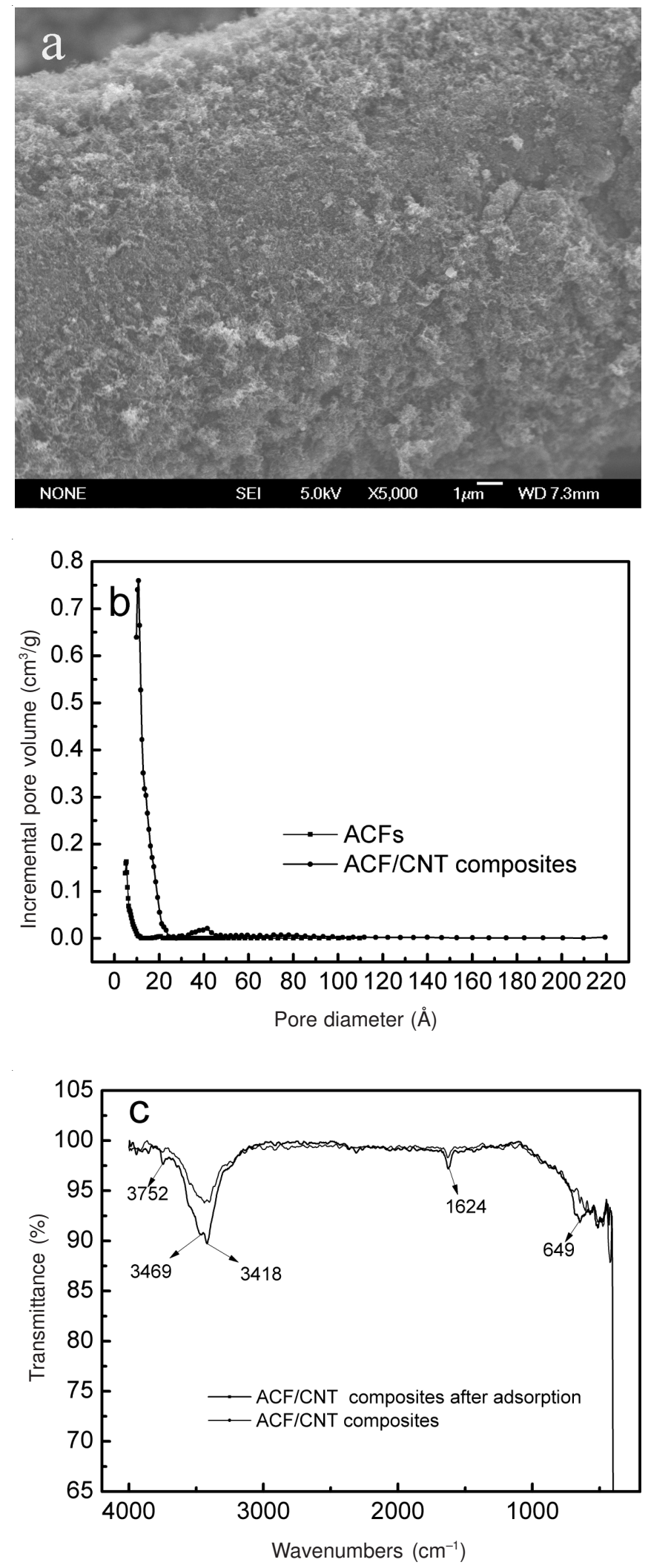


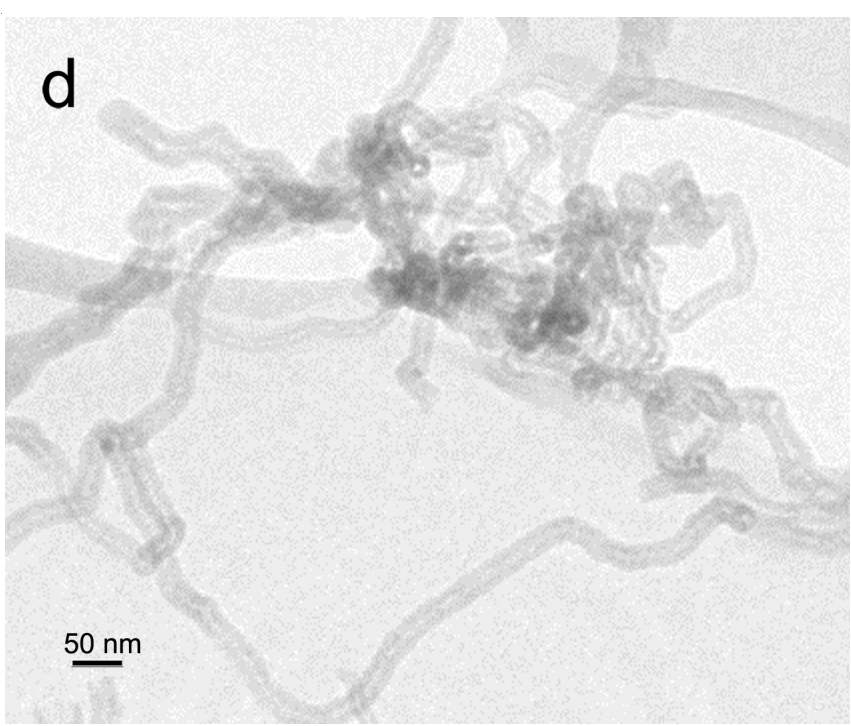

Fig. 2. SEM, pore size distribution, FTIR and HRTEM of the ACF/CNT composite

for rhodamine $\mathrm{B}$. The peak at $3752 \mathrm{~cm}^{-1}$ was assigned to the stretching vibration of free- $\mathrm{OH}$ and nearly not changed before and after adsorption. The peak at $1624 \mathrm{~cm}^{-1}$ was due to the stretching vibration of $\mathrm{C}=\mathrm{C}$ and increase slightly after adsorption. In addition, the adsorption band at $649 \mathrm{~cm}^{-1}$ was fingerprint region. HRTEM of ACF/CNT composites are shown in Fig. 2d which indicated ACFs were covered with CNTs.

Adsorption isotherms: The adsorption isotherm is the most important information, which indicates how adsorbate molecules are distributed between the liquid phase and solid phase when the adsorption process reaches equilibrium. In order to investigate the adsorption isotherms, two equilibrium models were used for analysis, namely the Langmuir and the Freundlich isotherm equations.

The expression of the Langmuir model is

$$
\frac{\mathrm{C}_{\mathrm{e}}}{\mathrm{q}_{\mathrm{e}}}=\frac{1}{\mathrm{q}_{0} \mathrm{~K}_{\mathrm{L}}}+\frac{1}{\mathrm{q}_{0}} \mathrm{C}_{\mathrm{e}}
$$

where $\mathrm{K}_{\mathrm{L}}$ and $\mathrm{q}_{0}$ represent the Langmuir constants that relate to the affinity of binding sites and the theoretical saturation capacity of the monolayer, respectively.

Freundlich isotherm linear equation is expressed as follows:

$$
\ln \mathrm{q}_{\mathrm{e}}=\ln \mathrm{K}_{\mathrm{F}}+\frac{1}{\mathrm{n}} \ln \mathrm{C}_{\mathrm{e}}
$$

where, $\mathrm{K}_{\mathrm{F}}$ and $\mathrm{n}$ are Freundlich constants, which represent adsorption capacity and adsorption strength, respectively.

The adsorption isotherm origin data of ACF/CNT composites for rhodamine B are demonstrated in Fig. 3a. It is seen that the equilibrium adsorption capacity increased with increasing the equilibrium concentration of solution due to the enhancement of diffusion concentration gradient and diffusion driving force with the rising of initial rhodamine B concentration. Moreover, Fig. 3 a also indicates that the equilibrium adsorption capacity improved when the temperature went up, suggesting that the adsorption of rhodamine B on ACF/CNT composites was favored at higher temperature.

The experimental data in Fig. 3a were fitted with Langmuir and Freundlich adsorption isotherm models and the fitting graphs are shown in Fig. $3 b$ and $3 c$, respectively. The related parameters were obtained by the linear regression analysis for Langmuir and Freundlich adsorption models and summarized in Table-1. The experimental data were well described by Langmuir isotherm adsorption model due to $\mathrm{R}^{2}>0.95$. In addition, the previous researches ${ }^{35}$ regarded $\mathrm{R}_{\mathrm{L}}$ as separation factor: (1) difficult $\left(\mathrm{R}_{\mathrm{L}}>1\right)$, (2) linear $\left(\mathrm{R}_{\mathrm{L}}=1\right)$, (3) favorable $\left(0<R_{L}<1\right)$, or (4) irreversible $\left(R_{L}=0\right)$. $R_{L}$ can be figured up according to the following equation:
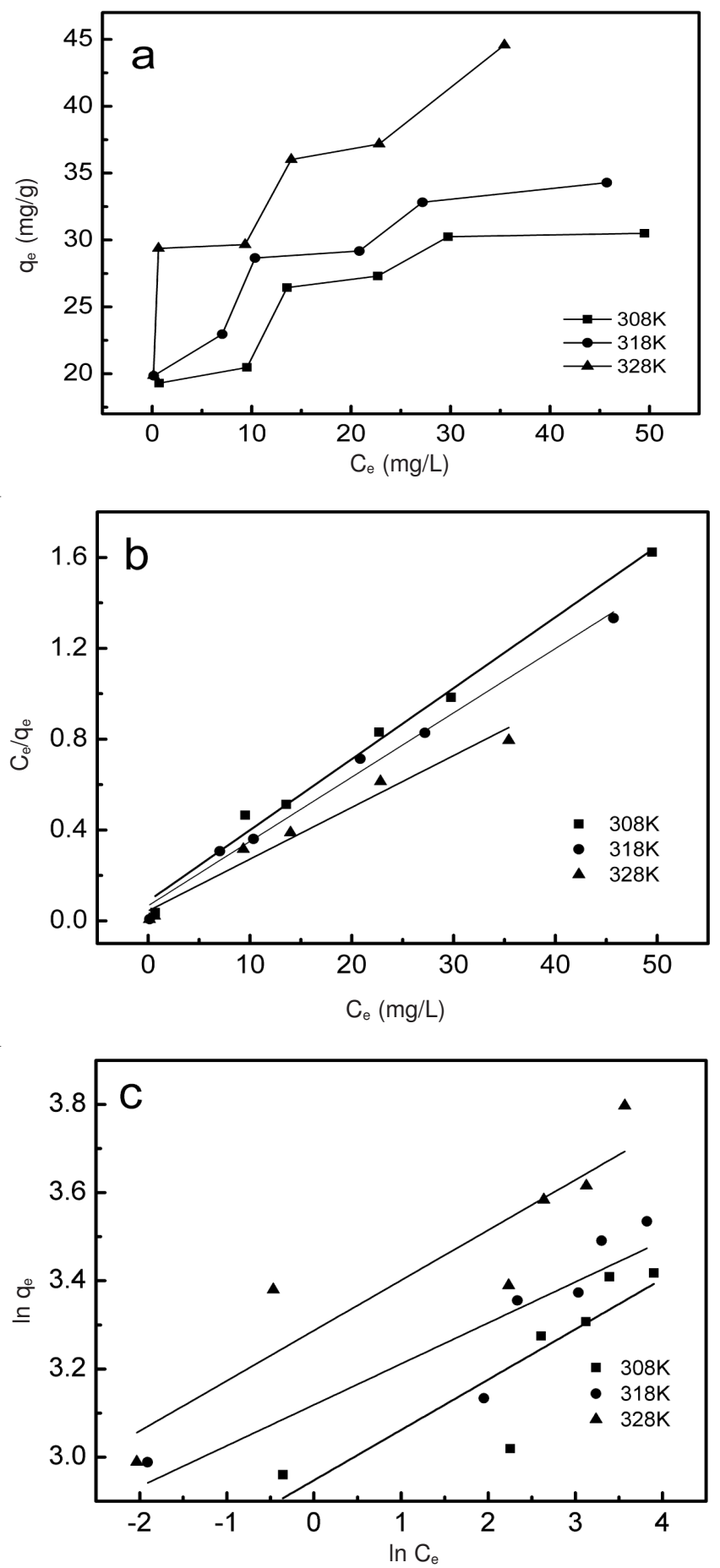

Fig. 3. Adsorption isotherms of ACF/CNT composites for rhodamine B: (a) initial data graph; (b) Langmuir isotherms and (c) Freundlich isotherms(conditions: $\mathrm{pH}, 4.4$; stirring rate, $120 \mathrm{rpm}$; contact time, $300 \mathrm{~min}$; adsorbent dose, $1 \mathrm{~g} / \mathrm{L}$ ) 


$$
\mathrm{R}_{\mathrm{L}}=\frac{1}{1+\mathrm{K}_{\mathrm{L}} \mathrm{C}_{0}}
$$

where, $\mathrm{K}_{\mathrm{L}}$ is Langmuir constant, $\mathrm{C}_{0}$ is the maximum rhodamine $\mathrm{B}$ initial concentration $(\mathrm{mg} / \mathrm{L})$.

The calculated values of $\mathrm{R}_{\mathrm{L}}$ at different experimental temperatures are listed in Table- $1.0<\mathrm{R}_{\mathrm{L}}<1$ implied the adsorption was favourable ${ }^{35}$.

TABLE-1

ISOTHERM PARAMETERS FOR REMOVAL OF RHODAMINE-B BY ACF/CNT COMPOSITES AT DIFFERENT TEMPERATURES

\begin{tabular}{ccccc}
\hline \multirow{2}{*}{ Isotherms } & \multirow{2}{*}{ Parameters } & \multicolumn{3}{c}{ Temperatures $(\mathrm{K})$} \\
\cline { 3 - 5 } & & 308 & 318 & 328 \\
\hline \multirow{5}{*}{ Langmuir } & $\mathrm{q}_{0}(\mathrm{mg} / \mathrm{g})$ & 32.0 & 35.3 & 43.9 \\
& $\mathrm{~K}_{\mathrm{L}}(\mathrm{L} / \mathrm{mg})$ & 0.358 & 0.424 & 0.521 \\
& $\mathrm{R}^{2}$ & 0.9880 & 0.9888 & 0.9679 \\
& $\mathrm{R}_{\mathrm{L}}$ & 0.0337 & 0.0286 & 0.0234 \\
\hline \multirow{5}{*}{ Freundlich } & $\mathrm{K}_{\mathrm{F}}(\mathrm{mg} / \mathrm{g}$ & 19.1 & 22.6 & 26.8 \\
& $\left.(\mathrm{~L} / \mathrm{mg})^{1 / \mathrm{n}}\right)$ & & & \\
& $\mathrm{n}$ & 8.76 & 10.8 & 8.78 \\
& $\mathrm{R}^{2}$ & 0.7126 & 0.7818 & 0.8047 \\
\hline
\end{tabular}

Adsorption kinetics: Adsorption rate is an important parameter in adsorption process. The bigger adsorption rate is, the faster adsorption reaches adsorption equilibrium, which results in the smaller adsorption equipment. Therefore, adsorption kinetic studies are important in the treatment of aqueous effluents. Generally, there are four steps for adsorption process: (a) adsorbate molecules diffuse from solution to liquid film on the surface of adsorbent; (b) pass through liquid film, which named liquid film diffusion; (c) diffuse into pores, which includes internal diffusion and surface diffusion and (d) are adsorbed on the internal surface of adsorbent. Among four steps, the slowest step controls adsorption rate. In order to determine the controlling mechanism of rhodamine $\mathrm{B}$ adsorbed onto $\mathrm{ACF} / \mathrm{CNT}$ composites, the adsorption data were analyzed in terms of pseudo-first-order, pseudo-second-order and intraparticle diffusion kinetics models.

The pseudo-first-order kinetic model equation is

$$
\ln \left(\mathrm{q}_{\mathrm{e}}-\mathrm{q}_{\mathrm{t}}\right)=\ln \mathrm{q}_{\mathrm{e}}-\mathrm{k}_{\mathrm{l}} \mathrm{t}
$$

where, $t$ is contact time ( $\mathrm{min}), \mathrm{q}_{\mathrm{t}}$ is adsorption capacity at time $\mathrm{t}(\mathrm{mg} / \mathrm{g}), \mathrm{k}_{1}$ is the first-order rate constant $\left(\mathrm{min}^{-1}\right)$. Values of $\mathrm{k}_{1}$ were calculated from the slope of the plots of $\ln \left(\mathrm{q}_{\mathrm{e}}-\mathrm{q}_{\mathrm{t}}\right)$ versus $\mathrm{t}$.

The pseudo-second-order kinetic model is expressed as

$$
\frac{\mathrm{t}}{\mathrm{q}_{\mathrm{t}}}=\frac{1}{\mathrm{k}_{2} \mathrm{q}_{\mathrm{e}}^{2}}+\frac{\mathrm{t}}{\mathrm{q}_{\mathrm{e}}}
$$

where, $k_{2}$ is the second-order rate constant [ $\left.\mathrm{g} /(\mathrm{mg} \min )\right]$. Values of $k_{2}$ were calculated from the plot of $t / q_{t}$ against $t$.

The intra-particle diffusion equation can be written by following:

$$
\mathrm{q}_{\mathrm{t}}=\mathrm{k}_{\mathrm{t}} \cdot \mathrm{t}^{1 / 2}+\mathrm{C}
$$

where, $\mathrm{C}$ is the intercept and $\mathrm{k}_{\mathrm{t}}$ is the intra-particle diffusion rate constant $\left[\mathrm{mg} /\left(\mathrm{g} \mathrm{min}^{0.5}\right)\right]$. According to this model, $\mathrm{q}_{\mathrm{t}}$ versus $\mathrm{t}^{1 / 2}$ should be linear if intra-particle diffusion is involved in the adsorption process. If these lines pass through the origin, thus intra-particle diffusion is the rate-controlling step. While the plots do not pass through the origin indicating that the adsorption mechanism is complex and the adsorption process contains both film diffusion and intra-particle diffusion ${ }^{36,37}$.

The adsorption kinetics initial data graphs are presented in Fig. 4a. The figure exhibits that the amount of rhodamine B adsorbed from aqueous solution increased with time and that the time for the adsorption of rhodamine $\mathrm{B}$ to reach equilibrium was $300 \mathrm{~min}$.

The pseudo-first-order, pseudo-second-order and intraparticle diffusion kinetics models were applied to fit the experimental data and the fitted curves are given in Fig. 4b, 4c and $4 \mathrm{~d}$, respectively. The regresses related parameters are listed in Table-2. The table shows the correlation coefficients for the pseudo-second-order kinetic model were higher than that of the first-order. An increase in the temperature also resulted slightly to increase in the calculated $\mathrm{q}_{2}$ values. These results implied that the adsorption of ACF/CNT composites for rhodamine B obeyed to the pseudo-second-order kinetic model.

From Fig. 4d, it is seen that the plots of $\mathrm{q}_{\mathrm{t}}$ versus $\mathrm{t}^{0.5}$ were linear, but not passed through the origin, which suggested the adsorption process was controlled by both film diffusion and intra-particle diffusion. The relevant parameters were regressed and given in Table- 2 . The value of $\mathrm{C}$ increased from 5.18 to 13.7 when the temperature raised from $35^{\circ} \mathrm{C}$ to $55^{\circ} \mathrm{C}$, expressing the increase in the diffusion layer thickness with the rise in the temperature.
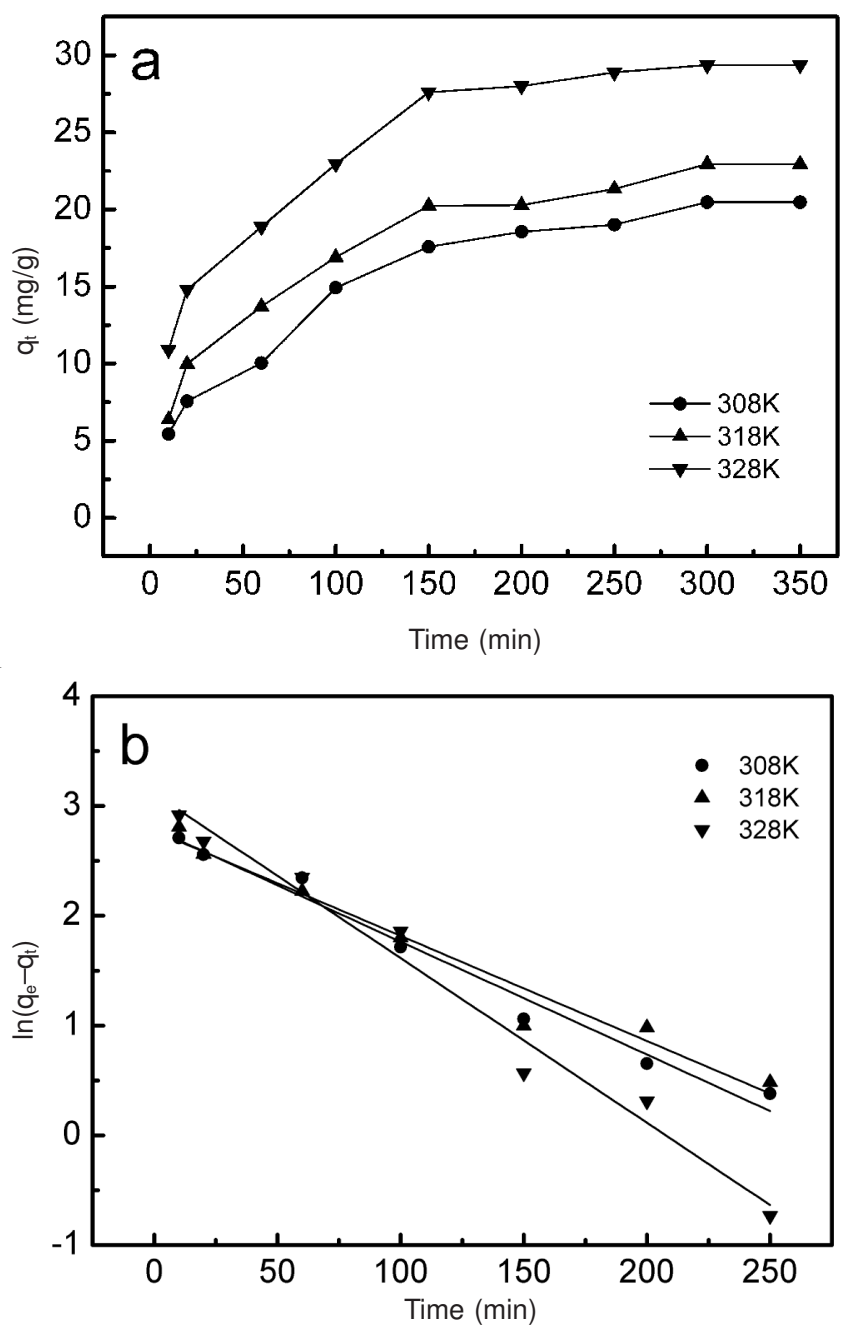

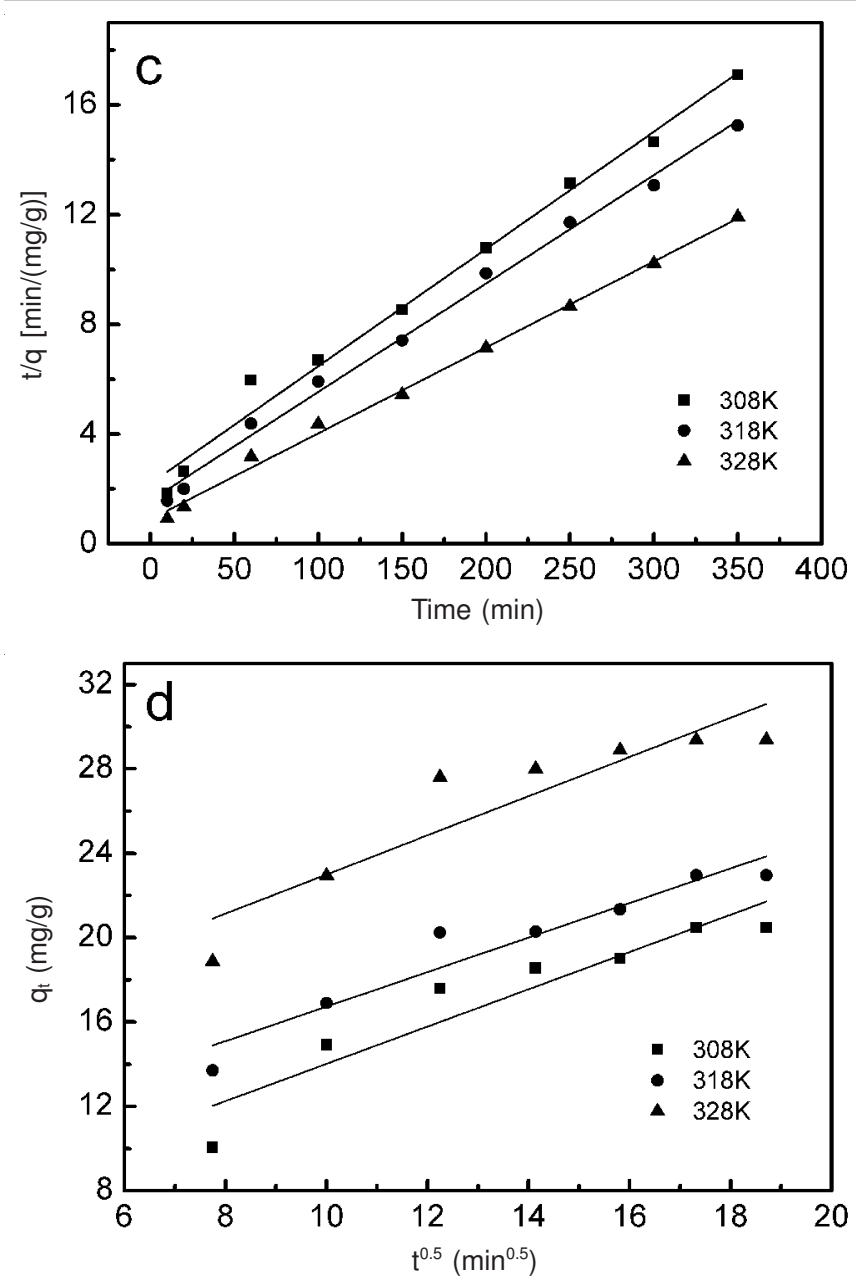

Fig. 4. Adsorption kinetics of ACF/CNT composites for rhodamine B: (a) initial data graph; (b) Pseudo-first order adsorption kinetics; (c) Pseudo-second order adsorption kinetics and (d) Intra-particle diffusion adsorption kinetics (conditions: $\mathrm{pH}, 4.4$; stirring rate, 120 $\mathrm{rpm}$; the initial concentration of rhodamine B, $30 \mathrm{mg} / \mathrm{L}$; adsorbent dose, $1 \mathrm{~g} / \mathrm{L}$ )

Adsorption thermodynamics: The thermodynamic parameters can reveal thorough information regarding the inherent energetic changes associated with adsorption. The thermodynamic parameters mainly include free energy of adsorption $(\Delta \mathrm{G})$, enthalpy $(\Delta \mathrm{H})$ and entropy $(\Delta \mathrm{S})$ changes and activation energy $\left(E_{a}\right)$ in adsorption process.

TABLE-2

KINETICS PARAMETERS FOR REMOVAL OF RHODAMINE-B BY ACF/CNT COMPOSITES AT DIFFERENT TEMPERATURES

\begin{tabular}{ccccc}
\hline Kinetics & Parameters & \multicolumn{3}{c}{ Temperatures $(\mathrm{K})$} \\
\cline { 3 - 5 } models & & 308 & 318 & 328 \\
\hline & $\mathrm{q}_{\text {exp }}(\mathrm{mg} / \mathrm{g})$ & 20.5 & 23.0 & 29.4 \\
Pseudo-first & $\mathrm{q}_{\mathrm{e}}(\mathrm{mg} / \mathrm{g})$ & 16.3 & 16.1 & 22.5 \\
order & $\mathrm{k}_{1}\left(\mathrm{~min}^{-1}\right)$ & 0.010 & 0.009 & 0.015 \\
& $\mathrm{R}^{2}$ & 0.9777 & 0.9596 & 0.9753 \\
\hline & $\mathrm{q}_{\mathrm{e}}(\mathrm{mg} / \mathrm{g})$ & 23.4 & 25.3 & 31.9 \\
Pseudo-second & $\mathrm{k}_{2} /[\mathrm{g} /$ & 0.000830 & 0.000989 & 0.00110 \\
order & $(\mathrm{mg} \mathrm{min})]$ & & & \\
& $\mathrm{R}^{2}$ & 0.9871 & 0.9940 & 0.9959 \\
\hline Intraparticle & $\mathrm{k}_{\mathrm{t}}$ & 0.884 & 0.819 & 0.929 \\
diffusion & $\mathrm{C}$ & 5.18 & 8.54 & 13.7 \\
model & $\mathrm{R}^{2}$ & 0.8616 & 0.9095 & 0.8110 \\
\hline
\end{tabular}

The Langmuir isotherm was adopted to calculate thermodynamic parameters using the following equations.

$$
\begin{gathered}
\Delta \mathrm{G}=-\mathrm{RT} \ln \mathrm{K}_{\mathrm{L}} \\
\Delta \mathrm{G}=\Delta \mathrm{H}-\mathrm{T} \Delta \mathrm{S}
\end{gathered}
$$

where, $\mathrm{R}$ is $8.314 \mathrm{~J} \mathrm{~mol}^{-1} \mathrm{~K}^{-1}, \mathrm{~T}$ is absolute temperature $(\mathrm{K})$, $\mathrm{K}_{\mathrm{L}}$ is Langmuir constant $(\mathrm{L} / \mathrm{mol}) . \Delta \mathrm{H}$ and $\Delta \mathrm{S}$ were determined from the intercept and slope of the plots of $\Delta \mathrm{G}$ versus $\mathrm{T}$ according to equation (9). The plots of $\Delta \mathrm{G}$ versus $\mathrm{T}$ are shown in Fig. 5a and the calculated thermodynamic parameters are given in Table-3. The values of $\Delta \mathrm{G}$ were positive, indicating that adsorption was nonspontaneous process. The value of $\Delta \mathrm{H}$ was $15.7 \mathrm{~kJ} / \mathrm{mol}(<40 \mathrm{~kJ} / \mathrm{mol})$, suggesting adsorption reaction was endothermic physisorption ${ }^{35,38}$. The positive value of $\Delta S$ demonstrated adsorption increased the disorder and chaos

\begin{tabular}{|c|c|c|c|c|}
\hline \multicolumn{5}{|c|}{$\begin{array}{c}\text { TABLE-3 } \\
\text { THERMODYNAMIC PARAMETERS FOR RHODAMINE-B } \\
\text { ADSORPTION ONTO ACF/CNT COMPOSITES }\end{array}$} \\
\hline $\mathrm{T}(\mathrm{K})$ & $\Delta \mathrm{G}(\mathrm{kJ} / \mathrm{mol})$ & $\Delta \mathrm{H}(\mathrm{kJ} / \mathrm{mol})$ & $\Delta \mathrm{S}[\mathrm{J} /(\mathrm{mol} \mathrm{K})]$ & $\mathrm{R}^{2}$ \\
\hline 308 & 2.63 & 15.7 & 42.5 & 0.9845 \\
\hline 318 & 2.27 & 15.7 & 42.5 & 0.9845 \\
\hline 328 & 1.78 & 15.7 & 42.5 & 0.9845 \\
\hline
\end{tabular}
degree of system $^{35}$.
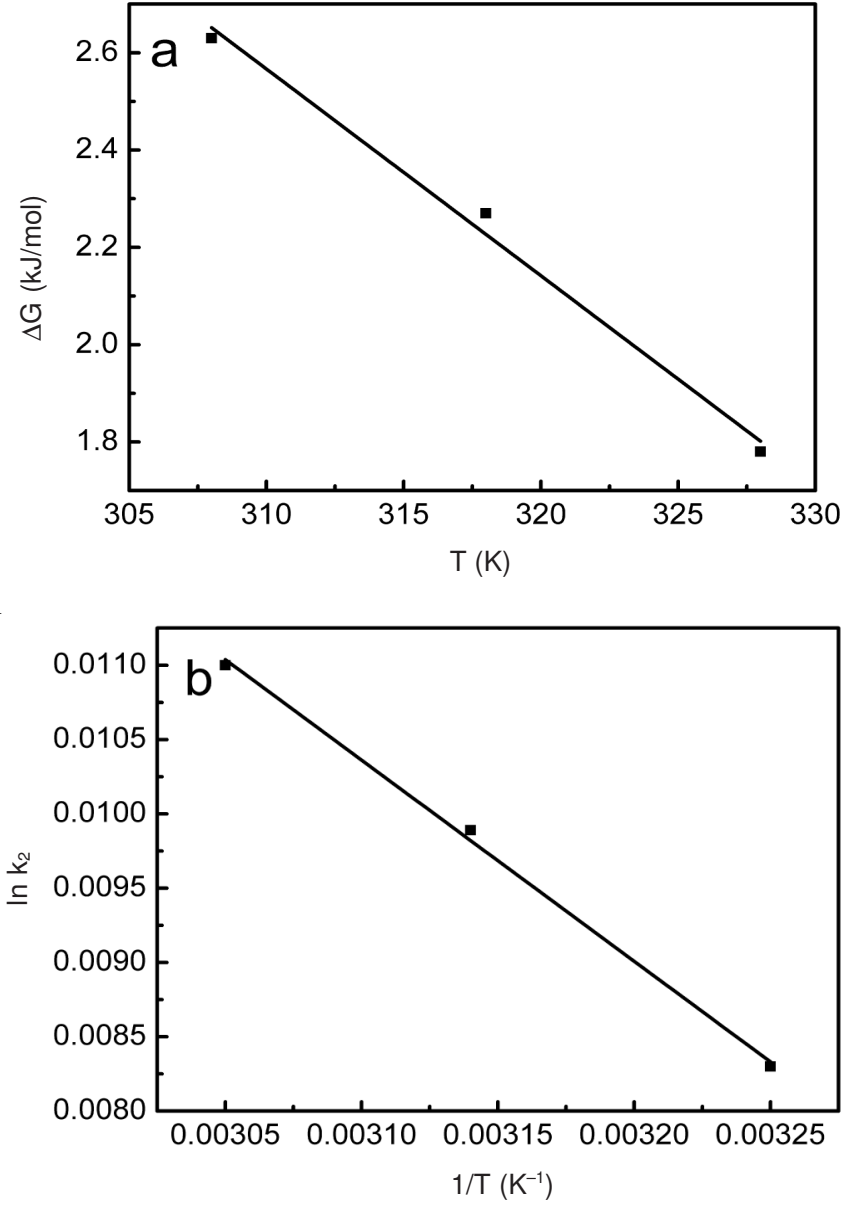

Fig. 5. Thermodynamic regression for rhodamine B adsorption onto ACF/CNT composites

The pseudo-second-order model was regarded as the best kinetic model for the adsorption of rhodamine $\mathrm{B}$ onto $\mathrm{ACF} /$ 
CNT composites. Accordingly, the rate constants $\left(\mathrm{k}_{2}\right)$ of the pseudo second-order model were used to calculate the adsorption activation energy according to the Arrhenius equation.

$$
\ln \mathrm{K}_{2}=\ln \mathrm{k}_{0}-\frac{\mathrm{E}_{\mathrm{a}}}{\mathrm{RT}}
$$

where, $\mathrm{k}_{2}$ is the rate constants of the pseudo second-order model $(\mathrm{g} / \mathrm{mg} \min ), \mathrm{k}_{0}$ is constant, $\mathrm{E}_{\mathrm{a}}$ is the adsorption activation energy $(\mathrm{kJ} / \mathrm{mol})$, $\mathrm{T}$ is temeperature $(\mathrm{K}), \mathrm{R}$ is $8.314 \mathrm{~J} / \mathrm{mol} \mathrm{K}$. The regressed plot of $\ln \mathrm{K}_{2}$ to $1 / \mathrm{T}$ is shown in Fig. $5 \mathrm{~b}$ according to eqn. 10 . The calculated value of $E_{a}$ was $0.113 \mathrm{~kJ} / \mathrm{mol}(0-40$ $\mathrm{kJ} / \mathrm{mol}$ ), which demonstrated the adsorption was physiosorption $^{35}$.

\section{Conclusion}

The fabrication of activated carbon fibre/carbon nanotube composites and their adsorption mechanism for rhodamine $\mathrm{B}$ from aqueous solution were discussed. The results showed that Langmuir isotherm adsorption model and the pseudosecond-order kinetic model could well describe the experimental data. The adsorption rate was controlled by both film diffusion and intra-particle diffusion. The values of $\Delta \mathrm{G}$ were positive, expounding the adsorption was non-spontaneous. The value of $\Delta \mathrm{H}$ was $15.7 \mathrm{~kJ} / \mathrm{mol}$, suggesting adsorption reaction was endothermic physisorption; the value of $\Delta \mathrm{S}$ was positive, indicating adsorption increased the disorder and chaos degree of system. Hydrogen bond was the main adsorption mechanism of activated carbon fibre/carbon nanotube composites for rhodamine B from aqueous solution.

\section{ACKNOWLEDGEMENTS}

This project was financially supported by the Foundation for Innovative Research Groups of the National Natural Science Foundation of China (Grant No. 51021063), the Science and Technology Plan Project of Hunan Province (2010FJ4075) and the Construct Program of the Key Discipline in Hunan Province.

\section{REFERENCES}

1. G. Afrane and O.-W. Achaw, Bioresour. Technol., 99, 6678 (2008).

2. Ö. Gerçel, H.F. Gerçel, A.S. Koparal and Ü.B. Ögütveren, J. Hazard. Mater., 160, 668 (2008).

3. C. Bradu, L. Frunza, N. Mihalche, S.-M. Avramescu, M. Neata and I. Udrea, Appl. Catal., B, 96, 548 (2010).

4. F.R. Furlan, L.G. de Melo da Silva, A.F. Morgado, A.A.U. de Souza and S.M.A. Guelli Ulson de Souza, Resour. Conserv. Recycl., 54, 283 (2010).
5. E. Guibal and J. Roussy, React. Funct. Polym., 67, 33 (2007).

6. K. Qi, Y. Wang, J. Chen, J. Li and S. Zhu, Sep. Purif. Technol., 57, 356 (2007).

7. S. Yang, F. Yang, Z. Fu, T. Wang and R. Lei, J. Hazard. Mater., 175, 551 (2010)

8. M. Šafaríková, L. Ptácková, I. Kibriková and I. Šafarík, Chemosphere, 59, 831 (2005).

9. T.H. Kim, C. Park and S. Kim, J. Clean. Prod., 13, 779 (2005).

10. K.M. Majewska-Nowak, J. Membr. Sci., 68, 307 (1992).

11. A. Akbari, S. Desclaux, J.C. Rouch, P. Aptel and J.C. Remigy, J. Membr. Sci., 286, 342 (2006).

12. J. Gao, X. Wang, Z. Hu, H. Deng, J. Hou, X. Lu and J. Kang, Water Res., 37, 267 (2003).

13. W. Lei, J. Hazard. Mater., 171, 577(2009).

14. Z. Shen, W. Wang, J. Jia, J. Ye, X. Feng and A. Peng, J. Hazard. Mater., 84, 107 (2001).

15. F. Yi, S. Chen and C. Yuan, J. Hazard. Mater., 157, 79 (2008).

16. Y. Dong, K. He, B. Zhao, Y. Yin, L. Yin and A. Zhang, Catal. Commun., 8, 1599 (2007).

17. S.K. Ling, S. Wang and Y. Peng, J. Hazard. Mater., 178, 385 (2010).

18. A.T. Sugiarto, S. Ito, T. Ohshima, M. Sato and J.D. Skalny, J. Electrostat., 58, 135 (2003).

19. N. Daneshvar, D. Salari and A.R. Khataee, J. Photochem. Photobiol. A, 162, 317 (2004).

20. M. Nikazar, K. Gholivand and K. Mahanpoor, Desalination, 219, 293 (2008).

21. R.J. Tayade, P.K. Surolia, R.G. Kulkarni and R.V. Jasra, Sci. Technol. Adv. Mater., 8, 455 (2007).

22. R. Yuan, S.N. Ramjaun, Z. Wang and J. Liu, Chem. Eng. J., 192, 171 (2012).

23. M.M. F. Silva, M.M. Oliveira, M.C. Avelino, M.G. Fonseca, R.K.S. Almeida and E.C. Silva Filho, Chem. Eng. J., 203, 259 (2012).

24. C.-H. Wu, J. Hazard. Mater, 144, 93(2007).

25. S. Xu, J. Wang, R. Wu, J. Wang and H. Li, Chem. Eng. J., 117, 161 (2006).

26. Y. Yu, Y.Y. Zhuang, Z.H. Wang and M.Q. Qiu, Chemosphere, 54, 425 (2004).

27. M.F. Hou, C.X. Ma, W.D. Zhang, X.Y. Tang, Y.N. Fan and H.F. Wan, J. Hazard. Mater., 186, 1118 (2011)

28. L. Li, S. Liu and T. Zhu, J. Environ. Sci. 22, 1273 (2010).

29. S.M. Al-Rashed and A.A. Al-Gaid, J. Saudi Chem. Soc., 16, 209 (2012).

30. L. Peng, P. Qin, M. Lei, Q. Zeng, H. Song, J. Yang, J. Shao, B. Liao and J. Gu, J. Hazard. Mater., 209, 193 (2012).

31. B. Pan and B. Xing, Environ. Sci. Technol., 42, 9005 (2008).

32. P.R. Chang, P. Zheng, B. Liu, D.P. Anderson, J. Yu and X. Ma, J. Hazard. Mater, 186, 2144 (2011).

33. C.Y. Kuo, C.H. Wu and J.Y. Wu, J. Colloid Interf. Sci., 327, 308 (2008).

34. N.S. Lawrence and J. Wang, Electrochem. Commun., 8, 71 (2006).

35. C.A.P. Almeida, N.A. Debacher, A.J. Downs, L. Cottet and C.A.D. Mello, J. Colloid Interf. Sci., 332, 46 (2009).

36. M.A. Al-Ghouti, M.A.M. Khraisheh, M.N.M. Ahmad and S. Allen, J. Hazard. Mater., 165, 589 (2009).

37. X. Han, W. Wang and X. Ma, Chem. Eng. J., 171, 1 (2011).

38. A.N. Fernandes, C.A.P. Almeida, N.A. Debacher and M.M. de Souza Sierra, J. Mol. Struct., 982, 62 (2010). 